\title{
The Politics of Women's Fashion in the Cultural West: A Perspective
}

\author{
Sarah E. Reynolds', Sophie V. Richardson', Max Barnish², Isla Reid³, Rachel Ross3 \\ Rhiannon Campbell ${ }^{4}$, Bex Horne ${ }^{5}$
}

${ }^{1}$ Independent Scholar, Glasgow, UK

${ }^{2}$ University of Exeter, Exeter, UK

${ }^{3}$ Independent Scholar, Edinburgh, UK

${ }^{4}$ Independent Scholar, Swansea, UK

${ }^{5}$ Independent Scholar, London, UK

Email: sarahereynolds2017@gmail.com
How to cite this paper: Reynolds, S. E., Richardson, S. V., Barnish, M., Reid, I., Ross, R., Campbell, R., \& Horne, B. (2017). The Politics of Women's Fashion in the Cultural West: A Perspective. Art and Design Review, 5, 252-257.

https://doi.org/10.4236/adr.2017.54021

Received: October 30, 2017

Accepted: November 25, 2017

Published: November 28, 2017

Copyright $\odot 2017$ by authors and Scientific Research Publishing Inc. This work is licensed under the Creative Commons Attribution International License (CC BY 4.0).

http://creativecommons.org/licenses/by/4.0/

\begin{abstract}
In this perspective piece, we discuss the politics of fashion in the cultural West. We cover issues of social expectation and individual freedom. We comment on where society draws the line with regard to public decency. We also comment on how the approach taken by society to health and public safety issues related to fashion differs markedly from that taken to other similar items.
\end{abstract}

\section{Keywords}

Fashion, Liberty, Society, Health, Safety, Social Influence

\section{Politics, the Individual, and Society}

A preliminary systematic review, albeit containing over seventy studies, conducted in 2010 (Muntaner et al., 2011) showed that social democracy was better for health than pro-market views such as conservatism (also known as neoliberalism). Yet, pro-market politics largely dominates the developed world currently. These approaches favor "leaving it to the market" as much as possible, and reducing the role of government, making it no surprise that in the UK for example, the Conservative Party (initially a Conservative-led coalition) government's "cutbacks in social provision are privatising work that is crucial to the substance of life" (Feminist Fightback Collective, 2011). The authors add that "the austerity measures of the... government will affect every facet of human life and relations; they are attempting to undermine the welfare state and to create a profoundly 
unequal society" (Feminist Fightback Collective, 2011). We cannot disagree, having seen how this program has unfolded over the intervening years, and see this as an intentional and ideological move (Bambra, 2013), that reflects highly politicized views about the role of the individual and the state, and indeed the value of human beings. Such views are not particularly distant from those that led to the Trump presidency or the Brexit vote, which are both travesties for public health, society and human civilization (Fahy et al., 2017; McKee et al., 2017). Although modern Conservatism in the West is largely respectful of individual freedom, and tends to prioritize this over the needs of society, situations in which individual freedom is not respected tend to be when it comes into tension with the interests of corporate business-indeed, it could be justifiably argued that the business sector ends up largely governing the country.

\section{Social Expectation and Individual Freedom in Women's Fashion in the West}

Issues regarding women's freedom of expression in what they wear are largely associated with areas of the world beyond the cultural West, largely the Arab world. No-one could sensibly claim that any issues with dress codes and freedom in the West come close to matching what is encountered in these other cultural spheres, where sometimes it is required for women to make themselves completely unrecognizable (Barikzai, 2016), and not through choice or for a costume party, but for everyday life. However, interestingly something like the veil can become so much part of a culture that some who are compelled to wear it no longer find it oppressive but "empowering" (Golnaraghi \& Dye, 2016). This shows the great power of politics and culture in shaping perceptions of normality.

Yet dress codes are a near-ubiquitous human civilization, and always constrain individual freedom to some extent. Indeed, fashion itself operates through socially normative processes, as discussed in the work of Barnish (Barnish \& Barnish, 2016; Barnish et al., 2017). Indeed, even in modern Western society, it is culturally accepted to require both men and women to wear particular items in certain settings. The question for society is solely where to draw the line, and this can be a matter of debate.

The biggest controversy in recent years has come around the issue of high heel wear, and this has powerful political overtones both in terms of gender equality, but also the power of the corporate sector who claim that not being able to control how employees look at work dilutes their brand power. A mass of evidence shows that high heel wear is detrimental to women's health (Barnish et al., 2017), yet some policymakers want to deny the strength of the evidence so as to not entertain compulsory high heel wear as a health protection issue, since it is politically inconvenient (M. Barnish, personal communication, 2017). It is difficult to know exactly where we stand as a society in ensuring women do not have to wear high heels when they do not wish to do so, but here is our analysis, 
greatly informed by the work and correspondence of Barnish. The most progressive policy development globally was surprisingly taken by a right-of-center government, which introduced Clause 8.22 to the British Columbia Occupational Health and Safety Regulation under the Workers Compensation Act (1996). Other countries largely continue to rely on generic equality legislation, whose interpretation currently is rather pro-business due to the political preferences of governing parties, and have not followed British Columbia's lead.

Yet these generic equality acts are largely considered, at least by governments, to make it illegal for employers to require women to wear high heels. Nevertheless, there have been issues with public awareness (not helped by confused media reporting of policy developments and lack of government clarity), compliance (but this varies by country-with the UK being where most of the issues arose), and also silence about door policies at public entertainment venues (covered by equality legislation in the UK under the "provision of goods and services" clause). Also, legislation cannot address implicit social pressure that operates through peer networks (Barnish et al., 2017). Formal social events are one area where choice may be constrained by unspoken social expectation, although choice is likely to be more than in the past.

Mass publicity around the work of Barnish has undoubtedly shaped public opinion, and "got into the ears" of employers, whereby at least in the UK, and hopefully elsewhere, it would now seem reputationally risky for employers outside very specific industries such as adult entertainment, modeling and acting to require high heels to be worn. Nevertheless, commentaries by Barnish and Morgan (2017) and Morgan and Barnish (2017) starkly reveal the limitations of the political response, likely to be shaped by governments not wanting to be seen to oppose the business community. Future governments may wish to take firmer action, but the political will is unknown, especially in the event of government change. Even the "socialist" government of France at the time was not prepared to take action to suspend the license of the Cannes Film Festival over requirements to wear high heels on the red carpet, and we shall have to see how that situation, that seems largely limited to that one event, progresses in time. High heels may be just the first of many debates about clothing, freedom and gender equality, although is a particularly major one given the health implications.

\section{Freedom and Public Decency}

Another area in which women's individual freedom in what they wear is politicized and culturally shaped is the concept of public decency. The definition is often circular, being partially defined by how others react. One controversial area has been the challenge for top free equality, critiquing how in some localities men can go shirtless but women cannot. Even within a single country, such as the USA, there can be federal differences (Begley, 2015). Largely in the West, it is acceptable for cleavage to be shown at adult-dominated social events, although there can be controversy in some settings such as TV shows depending 
on the locality. Yet big cleavage has been quite a fashion statement at smart social events recently (Reynolds, 2017) and something as spectacular as this (Just Jared, 2010) from 2010 is unlikely to be seen as shocking any more at the right event. Ultra short skirts are also usually tolerated at evening events in bars and clubs, even if they can lead to exposures of intimate areas that are not strictly in accordance with decency laws, showing the importance of cultural interpretation. The see-through fashion trend, which can reach extremes in celebrity circles, is also popular among certain young women, although it is rarely acceptable out with celebrity events to reach the level for example of Marnie Simpson of wearing a completely see-through dress commando (Fields, 2017).

\section{Individual Freedom, Fashion, and Public Safety}

Although even in the West, fashion is constrained by (fairly liberal) standards of public decency, no standards of public safety are usually enforced. This is despite a growing tendency for health and safety regulation that sometimes appears draconian and unnecessary. Yet, fashion is largely seen politically as a frontier not to be crossed in public safety policy. This is a very complicated area, and there are arguments on both sides (Reynolds, 2017). Yet, to not debate such matters seems remiss given the high frequency with which fashion items are encountered, often in crowded entertainment venues. The stiletto, for example, has been exempted from offensive weapons regulations in all major countries we know about, even though it has a sharp blade that derives from a medieval dagger. Sparkle is widely tolerated, even though it is defined to dazzle, which dictionaries define as "to blind temporarily" (Oxford Living Dictionary, undated), meaning that interfering with others' vision is allowed for the sake of glamour. Moreover, designers are starting to introduce dresses, and other items, featuring LED lights (LED Clothing Studio, 2016), which are beautiful but, when programmed to flash quickly, may disorientate others.

Similarly, although strict regulation of many trip hazards is common, most formal social events allow dresses with trains, although a few impose restrictions. Trains are glamorous and beautiful and do offer an exaggerated femininity, especially when they are long (Just Jared, 2016). Severe injuries due to stilettos and trains have been observed (Barnish et al., 2017; Kale, 2016; Mail Online Reporter, 2014; White, 2016), although the exact frequency is unknown. Clearly all these items have high social value, and are highly profitable for business, and that explains why they are off the political radar. Women would be sad to see them go, and that makes it politically risky to take action. Indeed, social norms may make it more likely for women to wear such items in certain circumstances, and make it hard for them to be aware of the risks and take them into consideration even if they are aware. This in turn may make transfer the responsibility for not being injured onto bystanders who need to be careful in where they walk, and in turn this may limit some other people's ability to fully partake in certain events. After all, social norms play a major role in influencing fashion and attitudes towards it. 


\section{Conclusion}

Politics, and political perspectives with regard to the relative roles and values of individuals, businesses, and society play an important role in shaping both what is acceptable in terms of fashion, and the social expectations women may face.

\section{References}

Bambra, C. (2013). The Primacy of Politics: The Rise and Fall of Evidence-Based Policy? Journal of Public Health, 35, 486-487. https://doi.org/10.1093/pubmed/fdt113

Barikzai, N. (2016). Afghan Women Still Bound By Burka. https://iwpr.net/global-voices/afghan-women-still-bound-burka

Barnish, M. S., \& Barnish, J. (2016). High-Heeled Shoes and Musculoskeletal Injuries: A Narrative Systematic Review. BMJ Open, 6, e010053. https://doi.org/10.1136/bmjopen-2015-010053

Barnish, M., \& Morgan, H. M. (2017). Are High Heels Bad For Your Health? Two Experts Review the Evidence. The Conversation, 3 August 2017.

Barnish, M., Morgan, H. M., \& Barnish, J. (2017). The 2016 HIGh Heels: Health effects And psychosexual Benefits (HIGH HABITS) Study: Systematic Review of Reviews and Additional Primary Studies. BMC Public Health, 18, 37.

https://doi.org/10.1186/s12889-017-4573-4

Begley, S. (2015). Here's Where It's Legal for Women to Go Topless in the U.S. http://time.com/3834365/map-topless-laws/

Fahy, N., Hervey, T., Greer, S., Jarman, H., Stuckler, D., Galsworthy, M. et al. (2017). How Will Brexit Affect Health and Health Services in the UK? Evaluating Three Possible Scenarios. Lancet [epub ahead of print]. https://doi.org/10.1016/S0140-6736(17)31926-8

Feminist Fightback Collective (2011). Cuts Are a Feminist Issue. Soundings, 49, 73-83. https://doi.org/10.3898/136266211798411165

Fields, S. E. (2017). Cultural and Aesthetic Analysis of Some of the Most Daring Celebrity Fashion Trends. Art and Design Review, 5, 103-114. https://doi.org/10.4236/adr.2017.52008

Golnaraghi, G., \& Dye, K. (2016). Discourses of Contradiction: A Postcolonial Analysis of Muslim Women and the Veil. International Journal of Cross Cultural Management, 16, 137-152. https://doi.org/10.1177/1470595816660118

Just Jared (2010). http://cdn03.cdn.justjared.com/wp-content/uploads/2010/01/carey-globes/mariah-care y-2010-golden-globe-awards-red-carpet-15.jpg

Just Jared (2016). Zoe Saldana’s Dolce \& Gabbana Met Gala 2016 Dress Has an Amazing Train!

http://www.justjared.com/photo-gallery/3646052/zoe-saldana-marco-perego-met-gala2016-03/

Kale, S. (2016). The Rise of Stilettos as Murder Weapons. https://broadly.vice.com/en_us/article/ae5bjp/the-rise-of-stilettos-as-murder-weapons

LED Clothing Studio (2016). Aurora Pixel LED Dress. https://www.youtube.com/watch?v=Bhs-WOaKPmo

Mail Online Reporter (2014). Here Comes the Vic-aaargh! Heart-Stopping Moment Reverend Trips Over and Breaks His Arm After Slipping on the Bride's Train as they Walk up the Aisle - Nearly Pulling Down Her Strapless Dress in Front of 80 Guests. 
http://www.dailymail.co.uk/news/article-2750534/Reverend-tripped-broke-arm-slippin g-bride-s-train.html

McKee, M., Greer, S. L., \& Stuckler, D. (2017). What Will Donald Trump's Presidency Mean for Health? A Scorecard. The Lancet, 389, 748-754. https://doi.org/10.1016/S0140-6736(17)30122-8

Morgan, H. M., \& Barnish, M. (2017). High Heels at Work: Does the Law Need Reformed? University of Aberdeen Law Blog, 3 August 2017.

Muntaner, C., Borrell, C., Ng, E., Chung, H., Espelt, A., Rodriguez-Sanz, M. et al. (2011). Politics, Welfare Regimes, and Population Health: Controversies and Evidence. Sociology of Health and Illness, 33, 946-964. https://doi.org/10.1111/j.1467-9566.2011.01339.x

Oxford Living Dictionary (Undated). https://en.oxforddictionaries.com/definition/dazzle

Reynolds, S. E. (2017). Boobs Out! A Perspective on Fashion, Sexuality and Equality. Art and Design Review, 5, 115-128. https://doi.org/10.4236/adr.2017.52009

White, S. (2016). How Stiletto Heels Became the Most Dangerous Weapon Used in Nightclub Attacks. Mirror, 21 March 2016. 